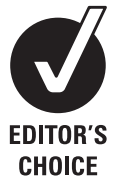

For numbered affiliations see end of article.

\section{Correspondence to}

Philippe Jonveaux, Laboratoire de Génétique, EA 4368-IFR111. Nancy Université, Centre Hospitalier et Universitaire (CHU) de Nancy, rue du Morvan, 54511 Vandoeuvre les Nancy, France; p.jonveaux@ chu-nancy.fr

Received 31 July 2009 Revised 26 October 2009 Accepted 9 November 2009

\title{
Microdeletion at chromosome 4q21 defines a new emerging syndrome with marked growth restriction, mental retardation and absent or severely delayed speech
}

\author{
C Bonnet, ${ }^{1}$ J Andrieux, ${ }^{2}$ M Béri-Dexheimer, ${ }^{1}$ B Leheup B, ${ }^{1,3} 0$ Boute, ${ }^{4}$ S Manouvrier, ${ }^{4}$ \\ B Delobel, ${ }^{5} \mathrm{H}$ Copin, ${ }^{6}$ A Receveur, ${ }^{6} \mathrm{M}$ Mathieu, ${ }^{7} \mathrm{G}$ Thiriez, ${ }^{8} \mathrm{C}$ Le Caignec, ${ }^{9}$ A David, ${ }^{9}$ \\ MC de Blois, ${ }^{10}$ V Malan, ${ }^{10,11}$ A Philippe, ${ }^{11,12}$ V Cormier-Daire, ${ }^{11,12}$ L Colleaux, $^{12}$ \\ E Flori, ${ }^{13} \mathrm{H}$ Dollfus, ${ }^{14}$ V Pelletier, ${ }^{14} \mathrm{C}$ Thauvin-Robinet, ${ }^{15}$ A Masurel-Paulet, ${ }^{15}$ \\ L Faivre, $^{15} \mathrm{M} \mathrm{Tardieu}^{16}{ }^{16}$ Bahi-Buisson, ${ }^{17} \mathrm{P}$ Callier, $^{18}{ }^{18}$ Mugneret $^{18}{ }^{18}$ Edery, ${ }^{19}$ \\ P Jonveaux, ${ }^{1}$ D Sanlaville ${ }^{19}$
}

\begin{abstract}
Background Genome-wide screening of large patient cohorts with mental retardation using microarray-based comparative genomic hybridisation (array-CGH) has recently led to identification several novel microdeletion and microduplication syndromes.

Methods Owing to the national array-CGH network funded by the French Ministry of Health, shared information about patients with rare disease helped to define critical intervals and evaluate their gene content, and finally determine the phenotypic consequences of genomic array findings.

Results In this study, nine unrelated patients with overlapping de novo interstitial microdeletions involving $4 q 21$ are reported. Several major features are common to all patients, including neonatal muscular hypotonia, severe psychomotor retardation, marked progressive growth restriction, distinctive facial features and absent or severely delayed speech. The boundaries and the sizes of the nine deletions are different, but an overlapping region of $1.37 \mathrm{Mb}$ is defined; this region contains five RefSeq genes: PRKG2, RASGEF1B, HNRNPD, HNRPDL

a large cohort of patients with mental retardation and dysmorphic features can help define a critical chromosome region that is unbalanced in several patients. The clinical descriptions of these patients can secondarily be compared to determine common phenotypic features. Some recurrent rearrangements were recently described: $17 \mathrm{q} 21.31$ deletion and duplication syndromes, 15q13.3 deletion syndrome, 15q24 deletion syndrome, 1q41q42 deletion syndrome, $2 \mathrm{p} 15 \mathrm{p} 16.1$ deletion syndrome and $9 \mathrm{q} 22.3$ deletion syndrome. ${ }^{1}$

We report here the clinical and molecular characterisation of a novel $4 \mathrm{q} 21$ microdeletion syndrome in nine unrelated individuals with a distinctive phenotype including severe mental retardation, absent or severely delayed speech, facial dysmorphism and marked progressive growth delay. We defined a $1.37 \mathrm{Mb}$ critical region containing five RefSeq genes and pinpointed to PRKG2 and RASGEF1B as the most promising candidate genes involved in the matched phenotypic features.
\end{abstract} and ENOPH1

Discussion Adding new individuals with similar clinical features and 4q21 deletion allowed us to reduce the critical genomic region encompassing two genes, PRKG2 and RASGEF1B. PRKG2 encodes CGMP-dependent protein kinase type II, which is expressed in brain and in cartilage. Information from genetically modified animal models is pertinent to the clinical phenotype. RASGEF1B is a guanine nucleotide exchange factor for Ras family proteins, and several members have been reported as key regulators of actin and microtubule dynamics during both dendrite and spine structural plasticity.

Conclusion Clinical and molecular delineation of $4 \mathrm{q} 21$ deletion supports a novel microdeletion syndrome and suggests a major contribution of PRKG2 and RASGEF1B haploinsufficiency to the core phenotype.

The recent use of microarray-based comparative genomic hybridisation (array-CGH) has accelerated the identification of novel cytogenetic abnormalities. In contrast to the earlier "phenotype-first" approach, array-CGH allows a "reverse dysmorphology". Combining array-CGH results from

\section{CLINICAL REPORTS}

The clinical characteristics of nine unrelated individuals with a de novo microdeletion involving $4 q 21$ are summarised in table 1 and were ordered by age at diagnosis ranging from 9 months in case 1 to 23 years in case 9 .

\section{Patient 1}

This girl was born at term with normal neonatal measurements: birth weight was $3180 \mathrm{~g}$ (25th-50th centile), length was $49 \mathrm{~cm}$ (25th-50th centile) and head circumference was $35.5 \mathrm{~cm}$ (75th-90th centile). In the neonatal period a severe hypotonia was noted. At the age of 8 months, her height was $66 \mathrm{~cm}(-1 \mathrm{SD})$, weight was $8200 \mathrm{~g}$ (median) and head circumference was $45 \mathrm{~cm}$ (1 SD); at the age of 14 months, her height was $70.5 \mathrm{~cm}(-1.5 \mathrm{SD})$, weight was $9750 \mathrm{~g}$ (median) and head circumference was $48 \mathrm{~cm}$ (2 SD). She had a large anterior fontanel, broad forehead, frontal bossing and hypertelorism. She had a flat nasal bridge, bulbous nasal tip, full 


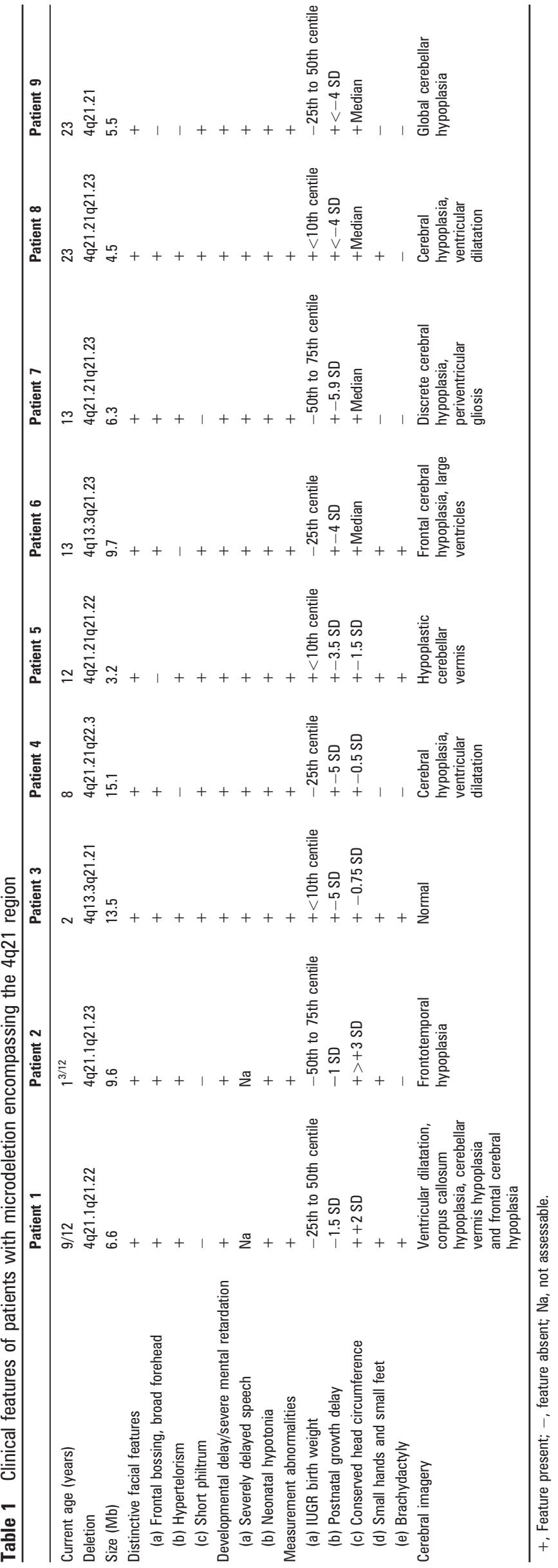

cheeks, long philtrum, thin lips and downturned corners of the mouth. She had a short neck, short limbs, small hands and feet, and brachydactyly. She showed a profound congenital deafness with small ear canal. Psychomotor development was delayed: at the age of 9 months, she was severely hypotonic and was unable to support her head or to sit unaided. Cerebral MRI showed large ventricles, hypoplasia of corpus callosum, hypoplasia of cerebellar vermis and frontal cerebral hypoplasia.

\section{Patient 2}

This 15 -month-old boy was born at 40 weeks of gestation with normal neonatal measurements: birth weight was $3310 \mathrm{~g}$ (50th-75th centile), length was $51 \mathrm{~cm}$ (75th-90th centile) and head circumference was $37 \mathrm{~cm}$ ( $>90$ th centile). At the age of 1 year, his height was $72 \mathrm{~cm}$ (-1SD), weight was $8900 \mathrm{~g}$ $(-1 \mathrm{SD})$ and head circumference was $51 \mathrm{~cm}(>3 \mathrm{SD})$. In addition to macrocephaly, a large anterior fontanel, high forehead, hypertelorism and epicanthus were noted. There were a wide nasal bridge, low-set ears, small mouth with downturned corners, small hands and feet and brachymetacarpy. He had dorsal kyphosis with hypoplastic dorsal vertebrae. He presented with global developmental delay: he was hypotonic, sat independently at the age of 15 months and had no speech. Cerebral MRI showed frontotemporal hypoplasia. Skeletal radiographies showed skeletal age delay, large anterior fontanel, abnormal metaphyses and epiphyses, and short long bones.

\section{Patient 3}

This boy was born after a pregnancy that was complicated by intrauterine growth retardation (birth weight was $<10$ th centile). He showed neonatal hypotonia, feeding problems in infants and seizures. Delayed epiphyseal ossification and delayed carpal ossification were noted in the neonatal period. At the age of 2 years, his height was $68 \mathrm{~cm}(-5 \mathrm{SD})$ and his head circumference was $48 \mathrm{~cm}(-0.75 \mathrm{SD})$. On clinical examination, he presented with a broad forehead, frontal bossing, hypertelorism, anteverted nostrils, full cheeks, short philtrum, downturned corners of the mouth, short neck, short limbs, small hands and feet, and brachydactyly. His psychomotor development was delayed: at the age of 24 months, he could only sit independently and was unable to speak. Cerebral MRI was normal. Skeletal radiographies showed abnormal modelling of distal phalanges (hands and feet), coxa valga with enlargement of the proximal femoral metaphyses, small epiphyses and short long bones.

\section{Patient 4}

This 8-year-old girl with mental retardation was the third child of healthy, non-consanguineous parents. The familial history was unremarkable. The pregnancy was complicated by hydramnios and fetal pleural effusion. Birth occurred by caesarean at 34 weeks of gestation. Birth weight was $1800 \mathrm{~g}$ (25th centile), length was $42 \mathrm{~cm}$ (10th-25th centile) and head circumference was $32.5 \mathrm{~cm}$ (75th centile). Apgar scores were 5, 8 and 8 at 1, 5 and $10 \mathrm{~min}$, respectively. The neonatal period was marked by hypotonia and respiratory distress. She underwent surgery for emphysema of inferior lobe of the left lung. She presented with severe scoliosis. Psychomotor development was severely delayed. At the age of 8 years, she was unable to walk and to speak. Cerebral MRI showed ventricular dilatation and discrete cerebral hypoplasia. At the age of 8 years, her height was $100 \mathrm{~cm}$ (-5 SD), weight was $16400 \mathrm{~kg}(-3 \mathrm{SD})$ and head circumference was $51 \mathrm{~cm}(-0.5 \mathrm{SD})$. On clinical examination, there were frontal bossing, bilateral ptosis, left microcoria, 
anteverted nostrils, short philtrum, low-set ears without lobule, short neck, and bilateral syndactyly of second and third toes and bilateral brachymesophalangy of fifth fingers.

\section{Patient 5}

This 12-year-old girl with mental retardation was born after a pregnancy complicated by intrauterine growth retardation (birth weight was $<10$ th centile) due to maternal hypertension. At birth, neonatal hypotonia, hypertrichosis and short limbs were noted. Psychomotor development was severely delayed: she walked at the age of 27 months and was unable to speak at the age of 12 years. Endocochlear sensorial deafness was noted. Neurological examination showed resting and intention tremors, hyperactive reflexes and wide-based, unstable gait. Brain MRI was normal at the age of 4 years; at the age of 10 years, brain MRI showed cerebellar vermis hypoplasia. At the age of 12 years, her height was $127 \mathrm{~cm}$ (-3.5 SD), weight was $37 \mathrm{~kg}$ (median) and head circumference was $51 \mathrm{~cm}$ (-1.5 SD); her hands and feet were small with syndactyly, brachydactyly and fetal pads. Facially, she had some distinctive features: hypertelorism, synophrys, very long eyelashes, long palpebral fissures, flat nasal bridge, anteverted nostrils, short philtrum, rolled up upper lip and short neck. Skeletal radiographies showed abnormal modelling of distal phalanges (hands and feet), coxa valga with enlargement of the proximal femoral metaphyses, small epiphyses and short femoral neck.

\section{Patient 6}

The boy was born at 39 weeks after an uneventful pregnancy. Birth weight was $2750 \mathrm{~g}$ ( $25 \mathrm{th}$ centile), length was $47 \mathrm{~cm}$ (25th centile) and head circumference was $35 \mathrm{~cm}$ (75th-90th centile). The neonatal period was marked by respiratory distress at day 2 with stridor due to laryngeal diplegia and neonatal hypotonia. There was severe psychomotor retardation: he walked at the age of 4 years and he remained unable to speak. Brain MRI at the age of 2 years showed frontal cerebral hypoplasia, ventricular dilatation and primary empty sella syndrome. At the age of 6 years, his height was $96.5 \mathrm{~cm}(<-4 \mathrm{SD})$ and his weight was $15 \mathrm{~kg}$ $(-2 \mathrm{SD})$, with a conserved head circumference of $52 \mathrm{~cm}$ (median). His hands and feet were small $(<3$ rd percentile and $<9$ th percentile) with brachydactyly. On physical examination at the age of 13 years, his height was $125 \mathrm{~cm}$ ( $-4 \mathrm{SD})$, weight was $34.2 \mathrm{~kg}(-1 \mathrm{SD})$ and head circumference was $54 \mathrm{~cm}$ (median). His face showed a broad and high forehead, frontal bossing, sparse and broad eyebrows, synophrys, horizontal palpebral fissures, wide nasal bridge, full cheeks, short philtrum, thin upper lip, small overlapping teeth and micrognathism. Mental retardation was considered as severe.

\section{Patient 7}

She was born at 38.5 weeks of gestation by caesarean: birth weight was $3130 \mathrm{~g}$ (50th-75th centile), length was $46 \mathrm{~cm}$ (10th -25 th centile) and head circumference was $34 \mathrm{~cm}$ (50th-75th centile). Neonatal period was marked by hypotonia, feeding problems and neonatal seizures. Psychomotor development was severely delayed: she could not walk and speak. Mental retardation was severe with behavioural troubles including selfaggressiveness and hetero-aggressiveness, repetitive stereotyped hand movements (hands clapping) and sleeping troubles. Cerebral MRI at the age of 5 years showed periventricular gliosis and discrete cerebral hypoplasia. At the age of 11 years, her height was $-5.9 \mathrm{SD}$. Facial features included a triangular face, broad forehead, hypertelorism, long slant down palpebral fissures, lowset posteriorly rotated ears and small mouth with downturned corners. Neurological examination showed hyperactive reflexes and upper limb flexor spasms. Skeletal radiographies showed abnormal modelling of distal phalanges (hands and feet), coxa valga with enlargement of the proximal femoral metaphyses, small epiphyses and scoliosis.

\section{Patient 8}

She was born with intrauterine growth retardation (birth weight was $<10$ th centile). Psychomotor development was severely delayed: she walked at the age of $5 \frac{1}{2}$ years and had severe language impairment. She used only a few words. CT of the brain showed ventricular dilatation and discrete cerebral hypoplasia. At the age of 19 years, her height was $137 \mathrm{~cm}$ (below $-4 \mathrm{SD}$ ) and her head circumference was $55 \mathrm{~cm}$ (median). On clinical examination, she presented with a broad and high forehead, frontal bossing, hypertelorism, hypoplastic alae nasi, short philtrum, and small hands and feet anomalies including brachymetatarsy.

\section{Patient 9}

This patient has been reported previously. ${ }^{2}$ This 23-year-old man was born at 39 weeks of gestation. His birth weight was $3020 \mathrm{~g}$ (25th-50th centile), length was $49 \mathrm{~cm}$ (50th centile) and head circumference was $34 \mathrm{~cm}$ (50th-75th centile). Pregnancy was marked by a toxoplasmic seroconversion between months 5 and 8 of gestation. At the age of 1 year, he developed postnatal short stature; at the age of 20 years, his height was $146 \mathrm{~cm}(<-4 \mathrm{SD})$, with normal bone age and normal head circumference. Facial features included convergent strabismus, short philtrum and retrognatism. He had Meckel diverticulum, ectopic testes, hypospadias, lumbar scoliosis and abnormal tooth position. Psychomotor development was severely delayed: he walked at the age of 4 years and spoke with only few words. Mental retardation is severe with behavioural problems including selfaggressiveness. He fulfilled the DSM IV criteria for autism. Two epileptic seizure episodes were noted at the age of 14 years. Neurological examination showed hyperactive reflexes and dyspraxia. Cerebral CT showed periventricular calcifications. At age 14 years, brain MRI showed global cerebellar hypoplasia.

\section{MATERIALS AND METHODS \\ Ascertainment of patients}

All patients were referred for array-CGH analysis by clinical geneticists. The patients took part in a clinical diagnostic testing for genomic imbalance using array-CGH following initial testing for karyotype (results normal). A collaborative study was set up, thanks to the national array-CGH network funded by the French Ministry of Health. Informed consents were available for all tested patients.

\section{Cytogenetic investigations}

Chromosome analysis was performed on peripheral blood lymphocytes by means of GTG banding. Fluorescence in situ hybridisation (FISH) experiments were conducted with bacterial artificial chromosomes (BAC) clones containing chromosome4-specific sequences (RP11-646K24 and RP11-450H10 for patient 2; RP11-57B24 for patient 5 and 6; RP11-449B1 for patients 3, 4 and 9; RP11-263F19 for patient 1 and 7; RP11-29L8 and RP11147K21 for patient 8), in accordance with publicly available genome resources (National Center for Biotechnology Information (NCBI) Map Viewer: http://www.ncbi.nlm.nih.gov; Santa Cruz Human Genome Browser: http://www.genome.ucsc.edu). BACs were obtained from the RPCI-11 library (BACPAC 
Table 2 Primer pairs used for quantitative real-time PCR

\begin{tabular}{lll}
\hline Gene & Forward primer $\left(\mathbf{5}^{\prime} \rightarrow \mathbf{3}^{\prime}\right)$ & Reverse primer $\left(\mathbf{5}^{\prime} \rightarrow \mathbf{3}^{\prime}\right)$ \\
\hline GK2 & TTCTCAGGATGGAACGATTTGA & TGTGGCATAACGAATTTCACTTTC \\
HNRPD & GGTGAAGTTGTAGACTGCACTCTGA & ACAAAGCCAAAACCCCTTGA \\
WDFY3 & GGCTGCTCGGTGAGGTTTT & GCTGACCACAGTTCCTGCAA \\
\hline
\end{tabular}

Resources Center, CHORI, Oakland, California, USA) and selected according to their positions on chromosomes 4. BAC DNAs were labelled by nick translation.

\section{Array-CGH analysis}

Array-CGH analysis was performed with the Agilent kit 44A for patients 5, 6 and 8 or 105A for patients 1, 2, 3, 4, 7 and 9 (Agilent Technologies, Santa Clara, California, USA). Genomic DNA was extracted from leucocytes of EDTA-treated peripheral blood using a manual procedure (OIAamp DNA midi kit, Qiagen, Hilden, Germany). The concentration and purity of the preparation were determined by measuring UV absorbance at 260 and $280 \mathrm{~nm}$. Hybridisation strategy used was hybridisation with a reference DNA for patients 1, 2, 5, 6 and 8; patient trios for patients 3, 4 and 9 (three patients are hybridised on three different arrays: patient 1 vs patient 2 on array 1 , patient 3 vs patient 2 on array 2 , and patient 1 vs patient 3 on array 3 ); and trios with parents from patient 7 (the patient is hybridised with the father on the first array and with the mother on the second array). DNAs (1 $\mu \mathrm{g})$ were double digested with RsaI and AluI (Promega, Madison, Wisconsin, USA) for $2 \mathrm{~h}$ at $37^{\circ} \mathrm{C}$. After inactivation of the enzymes at $65^{\circ} \mathrm{C}$, digested DNAs were labelled by random priming (Agilent Technologies) for $2 \mathrm{~h}$ at $37^{\circ} \mathrm{C}$ using Cy5-dUTP or Cy3-dUTP. Labelled products were column purified (Microcon YM30, Millipore, Bedford, MA). After probe denaturation and pre-annealing with $25 \mu \mathrm{g}$ of Cot 1 DNA (Invitrogen, Canada), hybridisation was performed at $65^{\circ} \mathrm{C}$ with rotation for $24 \mathrm{~h}(44 \mathrm{~A})$ or $40 \mathrm{~h}(105 \mathrm{~A})$. After two washing steps, the array was analysed with the Agilent scanner and the Feature Extraction software (v9.5.3.1). A graphical overview was obtained using the CGH analytics software (v3.5.14).

\section{Molecular investigations: real-time quantitative PCR}

Real-time quantitative PCR (qPCR) was performed on an ABI PRISM 7500 Sequence Detection System (Applied Biosystems, Foster City, California, USA). We designed three primer sets within the deleted region (table 2). qPCR was carried out in a total volume of $20 \mu \mathrm{L}$ containing $10 \mu \mathrm{L}$ of Fast SYBR Green Master Mix (Applied Biosystems), $0.4 \mu \mathrm{M}$ of each primer and $10 \mathrm{ng}$ of genomic DNA. Thermal cycling conditions were $95^{\circ} \mathrm{C}$ for $20 \mathrm{~s}$, followed by 40 cycles with $95^{\circ} \mathrm{C}$ for $3 \mathrm{~s}$ and $60^{\circ} \mathrm{C}$ for $30 \mathrm{~s}$. The RPPH1 gene was selected as the control amplicon.
Validation experiments demonstrated that amplification efficiency of the control and all target amplicons were approximately equal. All samples were run in triplicate. The dosage of each amplicon relative to RPPH1 and normalised to control DNA was determined using the $2^{-\Delta \Delta \mathrm{Ct}}$ method.

\section{RESULTS}

\section{Array-CGH analysis}

Array-CGH results (figure 1) are summed up in table 3 (NCBI March 2006 genome build). The shortest deletion is $3.2 \mathrm{Mb}$ in size (patient 5) and the longest is $15.1 \mathrm{Mb}$ in size (patient 4). The minimal critical region extends from 82228875 to 83601083 bp and includes five RefSeq genes: PRKG2, RASGEF1B, $H N R N P D, H N R P D L$ and ENOPH1 (figure 2). For validation experiments, the nine deletions were confirmed by FISH and/or qPCR in patients, while parents showed a normal result, proving the de novo occurrence of the nine deletions. The deleted genomic regions of the nine patients have never been described as copy number polymorphism in the database of genomic variants (http://projects.tcag.ca/variation/?source=hg18). Except for polymorphic regions, no copy number alterations were observed in other chromosomes (data not shown). None of the patients shared common breakpoints. In addition, the absence of segmental duplications at the proximal and distal breakpoint intervals suggested that these deletions were not generated by non-allelic homologous recombination.

\section{Clinical details of the studied subjects}

In three cases (patients 3,5 and 8), the pregnancy was complicated by intrauterine growth retardation. The youngest patients (patients 1 and 2) still have measurements within the normal range. Strikingly, a growth restriction combining postnatal short stature with conserved head circumference was noted in the seven other patients. Small hands and small feet were reported in the majority of cases (78\%), while brachydactyly was reported in four patients. In all patients, global psychomotor developmental delay was noted from an early age with a marked hypotonia. The level of developmental delay was estimated as severe. Three patients (3, 4 and 7) did not walk, and walking ability started after the age of 4 years in three other patients (6, 8 and 9). The speech and language development were particularly affected in all patients, with a profound speech deficit in five patients (3, 4, 5, 6 and 7). Congenital sensorial deafness was reported only in two individuals (1 and 5); this could be due to incomplete penetrance or to a second event on the other allele. Distinctive facial features present in the majority of the individuals included a broad forehead, frontal bossing, hypertelorism, a short philtrum and downturned corners of the mouth. Facial photographs of seven individuals

Table 3 Molecular features of patients with microdeletion encompassing the $4 \mathrm{q} 21$ region

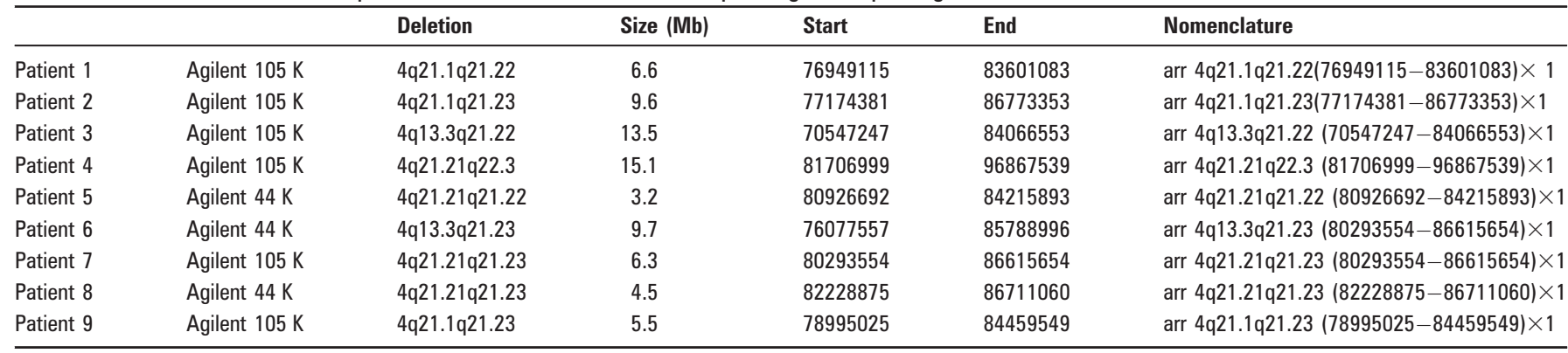

Data are from the National Center for Biotechnology Information March 2006 genome build. 


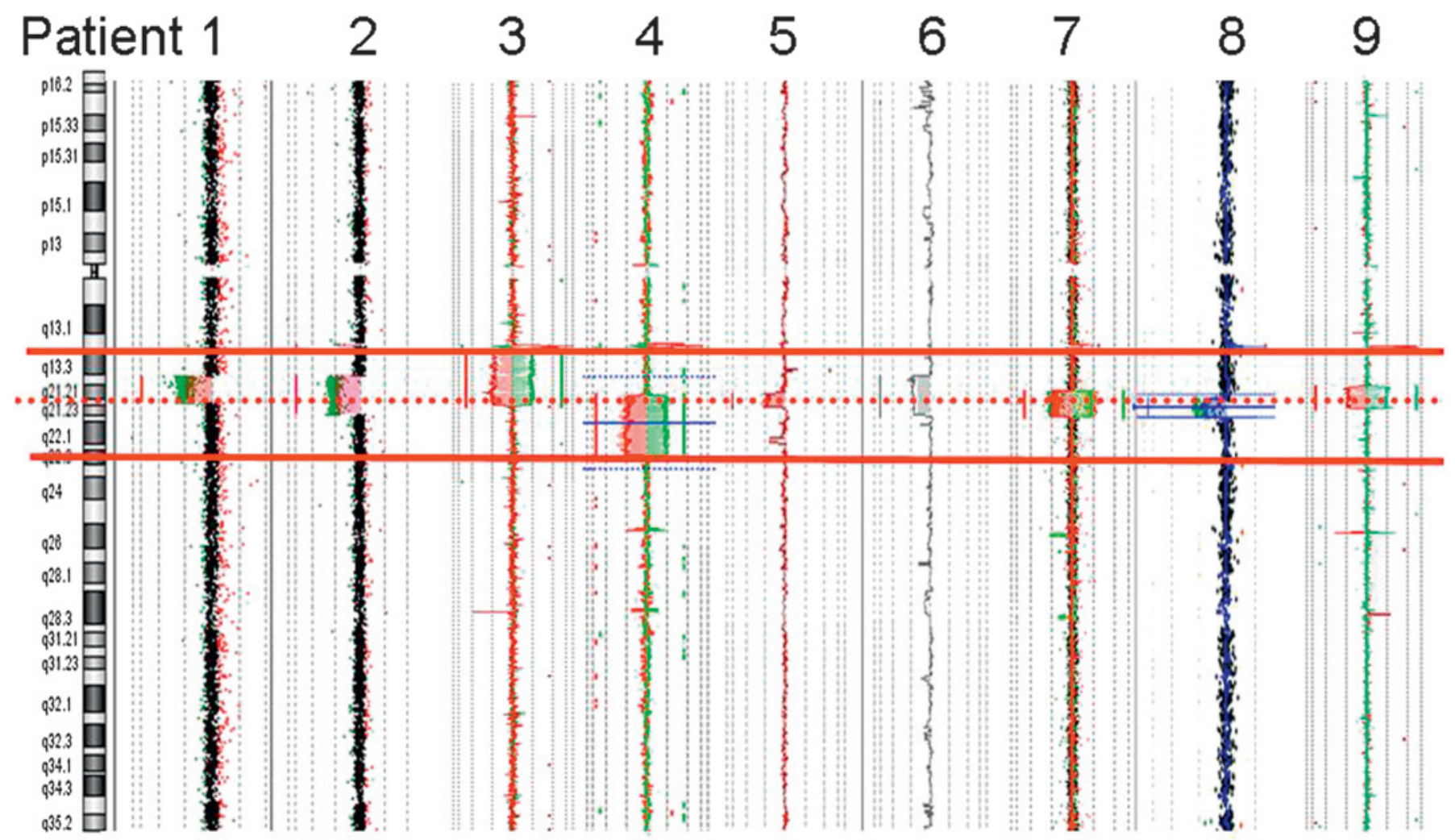

Figure 1 Array-CGH analysis of nine patients with microdeletion encompassing the 4q21 region: mapping of breakpoints and common deleted region (red dotted line).

are provided in figure 3. Behaviour problems were reported in two patients (7 and 9). Three patients (3,5 and 7) underwent a complete skeletal radiography examination, which showed common features: abnormal modelling of distal phalanges (hands and feet), coxa valga with enlargement of the proximal femoral metaphyses and small epiphyses. Cerebral imagery was abnormal in eight individuals, and demonstrated cerebral hypoplasia with ventricular dilatation in five individuals and cerebellar anomalies in three individuals.

\section{DISCUSSION}

We report on nine unrelated patients who display a common phenotype comprised of pronounced developmental delay or severe mental retardation and absence of speech, muscular hypotonia, severe growth restriction, distinctive facial features and variable brain anomalies. The common constellation of features is associated with a de novo interstitial deletion including region $4 \mathrm{q} 21$. The overlapping region of these nine deletions is $1.37 \mathrm{Mb}$ long and included five RefSeq genes: PRKG2, RASGEF1B, HNRNPD, HNRPDL and ENOPH1 (figure 2 and table 4). Interstitial deletions including chromosomal region 4q21 have already been described. Although the deleted regions among patients were different, most of them showed growth and developmental retardation. Notably, with few exceptions, most of the deletions have been characterised only at the cytogenetic level, which hampers a precise genotype-phenotype correlation in this region. The exact size of the deletion was determined for only five cases (table 5). Harada et al ${ }^{3}$ reported a girl with del(4)(q21.1q22.2) and severe postnatal short stature $(-7.4 \mathrm{SD}$ at 6.6 years of age), delayed bone age and severe psychomotor retardation including an absence of speech ability. Other abnormalities included a dolichocephaly, hypertelorism, long philtrum, small mouth, defect of the bilateral lower incisors, pathological attrition of all teeth, bilateral sensorial deafness with ear canal stenosis and muscle hypotonia. Karyotype and FISH analysis using BAC clones revealed a 4q21.1q22.2 de novo deletion extending from 81 to $95.8 \mathrm{Mb}$. This deletion includes the five RefSeq genes commonly deleted in our reported cases. Friedman et al ${ }^{4}$ studied 100 children with idiopathic mental retardation and identified a 4q21.21q22.1 de novo deletion extending from 82.1 to $93.2 \mathrm{Mb}$ in an 18-year-old girl with extremely short stature, small hands and feet, severe hypotonia, mild scoliosis and severe cognitive impairment. The face showed deep-set eyes with narrow palpebral fissures, low-set and straight eyebrows, narrow nasal root, columella below alae nasi, and short philtrum. This deletion includes also the five RefSeq genes.

Two DECIPHER-reported cases overlap with our cases: patients 1571 and 4539 (data from Drs Emilia Bijlsma (Leiden University Medical Center, Leiden, The Netherlands) and MarieClaude Addor (Centre Hospitalier Universitaire Vaudois, Lausanne, Switzerland). These two patients all present with developmental and postnatal growth delay (table 5). The deletion of case 1571 (figure 3) was detected with a $1 \mathrm{Mb}$ clone array. The telomeric boundary is between positions 82332981 and $83182488 \mathrm{bp}$. Thus, this deletion can reduce the critical region: the maximal region includes $P R K G 2$ and $R A S G E F 1 B$, and the minimal region only includes the PRKG2 gene. It is possible that other genes in these large deletions are contributing to the variability of congenital defects seen in these individuals. Regarding the critical region, we focused on the RASGEF1B and PRKG2 genes.

$R A S G E F 1 B$ is a highly conserved guanine nucleotide exchange factor for Ras family proteins. Ras superfamily proteins function 
A

Overvieu of chr4

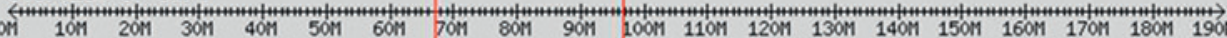

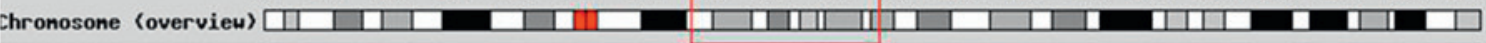

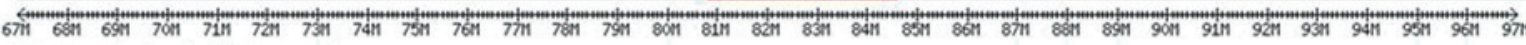

\begin{tabular}{l} 
Cytogenetic Bands (Chronosone) \\
4q13.2 \\
\hline${ }_{4 q 13.3}$
\end{tabular}

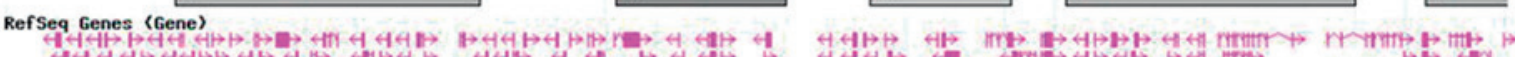

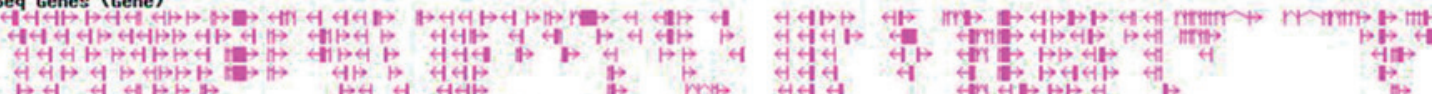

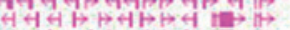

समझ समHPP

索
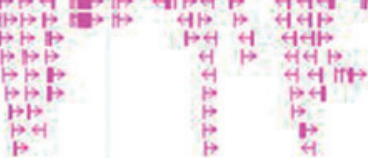

$\rightarrow$ init
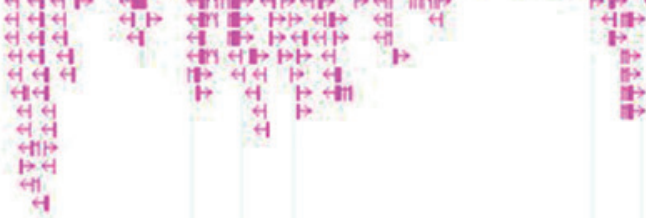

Overlapping_region

Present_cases

Present_case_and_previous_cases

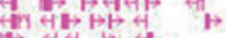

丞然点

DECIPHER_1571

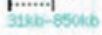

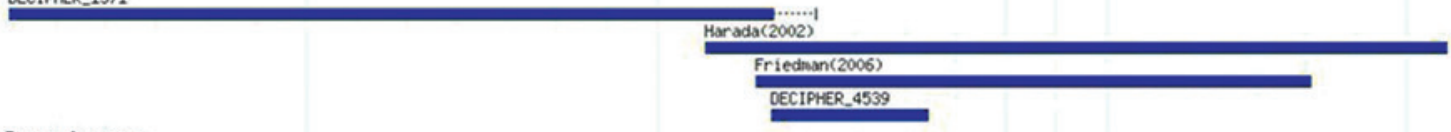

Present_cases

Patient_-3

Patient_6

Patient_1

Patient_9

Patient_7

Patient_5

Patient_4

Patient_8

B

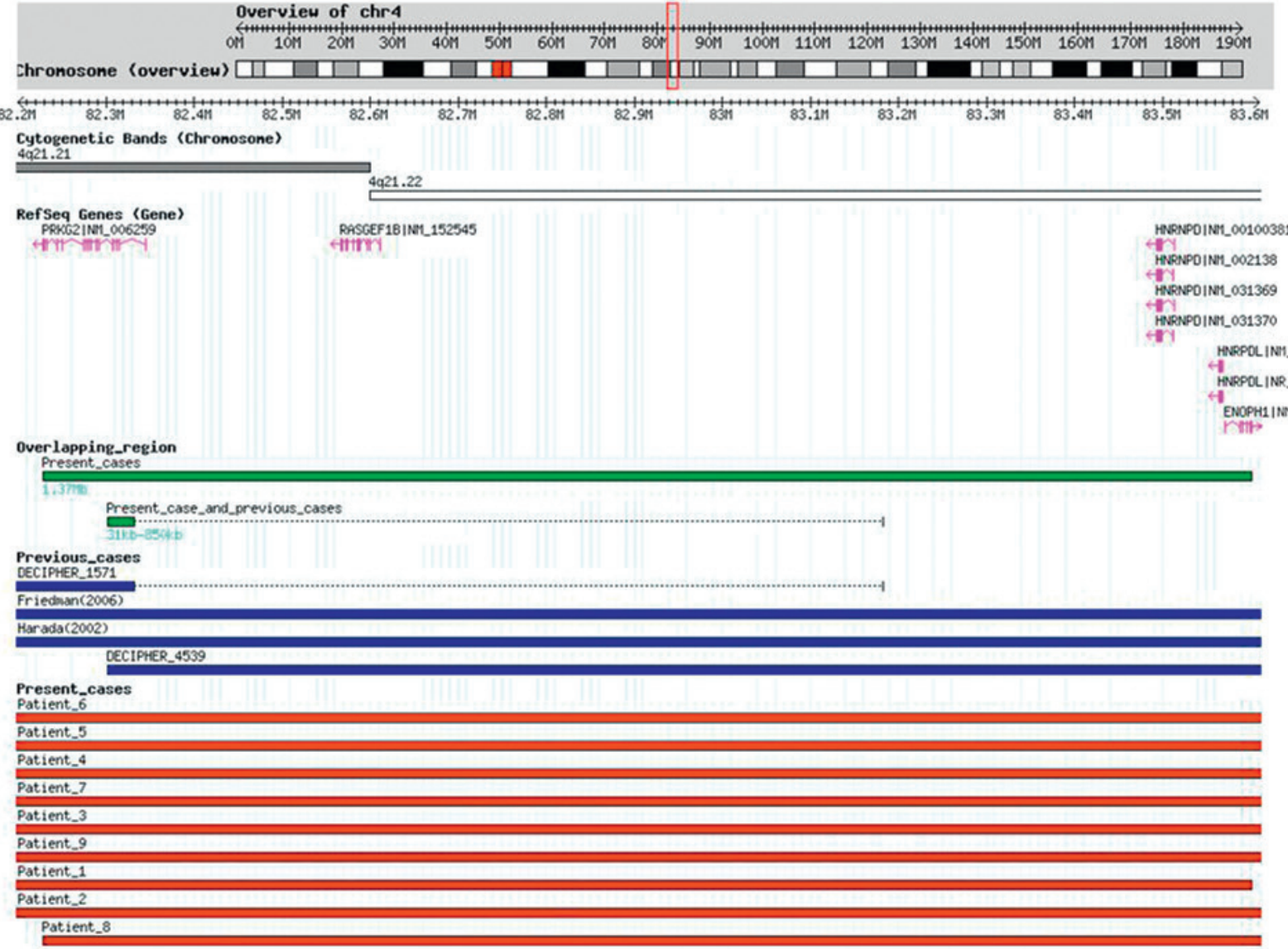

Figure 2 Map of the deleted region (National Center for Biotechnology Information March 2006 genome build). (A) Region 4q13.2q22.3. (B) Zoomed view showing the 4q21.21q21.22 region. 

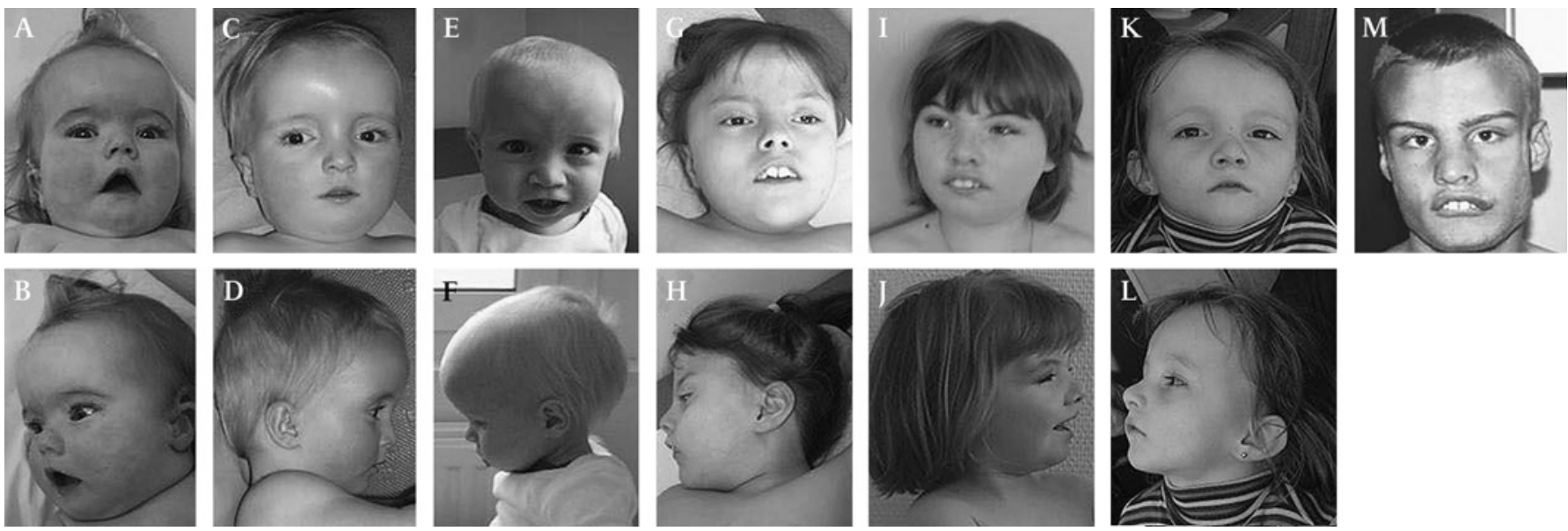

Figure 3 Front and lateral views of seven patients with microdeletion encompassing the $4 q 21$ region. (A and $B)$ Patient $1 ;(C$ and $D)$ patient 2; $(E$ and F) patient 3; ( $\mathrm{G}$ and $\mathrm{H})$ patient 4 ; (I and J) patient 5 ; (K and $\mathrm{L})$ patient 7 ; $(\mathrm{M})$ patient 9 . Parental informed consent was obtained for the publication of this figure.

as molecular switches in fundamental events such as signal transduction, cytoskeleton dynamics and intracellular trafficking. RASGEF1B shows a high level of central nervous system expression (Genecards) and is, therefore, a good candidate for the central nervous system phenotype. A growing number of genes that are related to mental retardation have been involved in Rho-GTPase signalling pathways. ${ }^{5}$ Among them, ARHGEF6 and FGD1 encode guanine nucleotide exchange factors and regulate Rac and Cdc42, two members of the Rho family of small GTPases, which are considered as key regulators of actin and microtubule dynamics during both dendrite and spine structural plasticity. $^{6}$

PRKG2 encodes cGMP-dependent protein kinase type II (cGKII). cGKII is a membrane-bound kinase, which is activated by intracellular cGMP, and is known to be expressed abundantly in the intestinal mucosa, kidney, lung, brain and cartilage. Pfeifer et $\mathrm{al}^{7}$ generated mice carrying a null mutation of the cGKII gene (cGKII-/- mice); these mice developed postnatal dwarfism that was caused by a severe defect in endochondral ossification at the growth plates and impaired chondrocyte hypertrophy. Chikuda et $a l^{8}$ described the Komeda miniature rat Ishikawa. This rat is a naturally occurring mutant caused by an autosomal recessive mutation mri. They identified the mri mutation as a deletion in cGKII. The Komeda miniature rat Ishikawa exhibited longitudinal growth retardation and showed expanded growth plates.

Kugimiya et $a l^{9}$ and then Kawasaki et al ${ }^{10}$ investigated the mechanism of cGKII-mediated chondrocyte hypertrophy. cGKII phosphorylates glycogen synthase kinase-3 $\beta$ (GSK-3 $\beta$ ). Phosphorylation inactivates GSK-3 $\beta$. GSK-3 $\beta$ is a negative regulator of $\beta$-catenin through its phosphorylation and degradation. When GSK-3 $\beta$ is phosphorylated and inactivated, $\beta$-catenin level increases and $\beta$-catenin can go into the nucleus to enhance chondrocyte hypertrophy. cGKII also phosphorylates Sox9, an inhibitor of chondrocyte hypertrophy, and suppresses its nuclear entry, leading to enhancement of chondrocyte hypertrophy. Chondrocyte hypertrophy in the growth plates is a rate-limiting step for longitudinal skeletal growth. In $\mathrm{cGKII}^{-/-}$mice, chondrocyte hypertrophy and elongation of growth plates are impaired, resulting in postnatal dwarfism. These experimental data provide support to the hypothesis that haploinsufficiency of PRKG2 could explain severe growth delay observed in the reported patients. Additionally, Ulher ${ }^{11}$ showed that cGKII transcript is abundant in brain. Serulle et al ${ }^{12} 13$ also showed that cGKII and GluR1 form a complex in brain; more specifically in this complex, cGKII can phosphorylate GluR1, leading to increased GluR1 surface levels and to the surface expression of AMPA receptors at extrasynaptic sites. This mechanism plays an important role in long-term potentiation in the hippocampal neurons, a critical step involved in learning and memory. GluR1 accumulation in the plasma membrane also plays a pivotal role in synaptic plasticity. Therefore, PRKG2 haploinsufficiency could also participate to the severe cognitive developmental delay reported in patients with 4q21 microdeletion.

In summary, we have characterised a novel microdeletion syndrome at chromosome $4 \mathrm{q} 21$ with a recognisable clinical phenotype including severe mental retardation, absent speech, distinctive facial features and severe growth delay. In the minimal critical region, we identified PRKG2 and RASGEF1B as major determinants of the $4 \mathrm{q} 21$ deletion phenotype. Further detailed clinical examination of additional patients with a similar microdeletion is needed to get more insight into the phenotype and to establish guidelines for anticipatory healthcare management across the lifespan.

Table 4 List of genes within the common deleted region

\begin{tabular}{|c|c|c|c|c|c|}
\hline Start & Stop & Symbol & Model evidence & Cyto & Description \\
\hline 82228861 & 82345239 & PRKG2 & Best RefSeq & $4 q 13.1 q 21.1$ & Protein kinase, cGMP-dependent, type II \\
\hline 82567243 & 82612085 & RASGEF1B & Best RefSeq & $4 q 21.21 q 21.22$ & RasGEF domain family, member 1B \\
\hline 83493491 & 83514173 & $H N R P D$ & Best RefSeq & $4 q 21.1 q 21.2$ & $\begin{array}{l}\text { Heterogeneous nuclear ribonucleoprotein } \mathrm{D} \text { (AU-rich } \\
\text { element RNA binding protein } 1.37 \mathrm{kDa} \text { ) }\end{array}$ \\
\hline 83563371 & 83570402 & HNRPDL & Best RefSeq & $4 q 13 q 21$ & Heterogeneous nuclear ribonucleoprotein D-like \\
\hline 83570787 & 83601264 & ENOPH1 & Best RefSeq & $4 q 21.22$ & Enolase-phosphatase 1 \\
\hline
\end{tabular}

Data are from http://www.ncbi.nlm.nih.gov/mapview/maps.cgi?ORG=hum, build 36.3. 
Table 5 Clinical features of individuals with overlapping microdeletion previously reported in the literature

\begin{tabular}{|c|c|c|c|c|}
\hline & $\begin{array}{l}\text { Patient } 10 \\
\text { DECIPHER } \\
1571\end{array}$ & $\begin{array}{l}\text { Patient } 11 \\
\text { DECIPHER } \\
4539\end{array}$ & $\begin{array}{l}\text { Patient } 12 \\
\text { Friedman } \\
\text { et } a I^{4}\end{array}$ & $\begin{array}{l}\text { Patient } 13 \\
\text { Harada } \\
\text { et } \mathrm{al}^{3}\end{array}$ \\
\hline Deletion & $4 q 13.2 q 21.21$ & $4 q 21.21 q 21.23$ & $4 q 21.21 q 22.1$ & $4 q 21.1 q 22.2$ \\
\hline Size (Mb) & 15 & 3.2 & 11 & 14.8 \\
\hline $\begin{array}{l}\text { Distinctive facial } \\
\text { dysmorphism }\end{array}$ & ND & + & ND & + \\
\hline $\begin{array}{l}\text { (a) Frontal bossing, } \\
\text { broad forehead }\end{array}$ & & & & - \\
\hline (b) Hypertelorism & & & & + \\
\hline (c) Short philtrum & & & + & - \\
\hline $\begin{array}{l}\text { Developmental } \\
\text { delay/severe mental } \\
\text { retardation }\end{array}$ & ND & + & + & + \\
\hline $\begin{array}{l}\text { (a) Severely delayed } \\
\text { speech }\end{array}$ & + & + & ND & + \\
\hline $\begin{array}{l}\text { (b) Neonatal } \\
\text { hypotonia }\end{array}$ & ND & + & + & + \\
\hline $\begin{array}{l}\text { Measurement } \\
\text { abnormalities }\end{array}$ & + & + & + & + \\
\hline (a) IUGR & ND & - & ND & - \\
\hline $\begin{array}{l}\text { (b) Postnatal growth } \\
\text { delay }\end{array}$ & + & + & + & $\begin{array}{l}+ \\
-7.4 \mathrm{SD}\end{array}$ \\
\hline $\begin{array}{l}\text { (c) Conserved head } \\
\text { circumference }\end{array}$ & ND & + & ND & ND \\
\hline $\begin{array}{l}\text { (d) Small hands and } \\
\text { small feet }\end{array}$ & & + & + & \\
\hline (e) Brachydactyly & & & & \\
\hline Cerebral imagery & ND & ND & ND & ND \\
\hline
\end{tabular}

+ , Feature present; -, feature absent; ND, no data available.

IUGR (intrauterine growth retardation).

\section{Web resources}

- NCBI Map Viewer: http://www.ncbi.nlm.nih.gov/mapview/ maps.cgi?ORG $=$ hum

- UCSC: Santa Cruz Human Genome Browser: http://www. genome.ucsc.edu

- DGV: Database of Genomic Variants: http://projects.tcag.ca/ variation/

- DECIPHER: DatabasE of Chromosomal Imbalance and Phenotype in Humans using Ensembl Resources: https://decipher. sanger.ac.uk/

- GENECARDS: http://www.genecards.org/

\section{Author affiliations:}

'Laboratoire de Génétique, EA 4368-IFR111, Nancy Université, Centre Hospitalier et Universitaire (CHU) de Nancy, Nancy, France

${ }^{2}$ Laboratoire de Génétique Médicale, Hôpital Jeanne de Flandre, CHU de Lille, Lille, France

${ }^{3}$ Service de Médecine Infantile III et Génétique Clinique, CHU de Nancy, Nancy, France ${ }^{4}$ Service de Génétique Clinique, Hôpital Jeanne de Flandre, CHU de Lille, Lille, France ${ }^{5}$ Centre de Génétique Chromosomique, Hôpital St Vincent de Paul, Lille, France

${ }^{6}$ UF de Cytogénétique, Centre de Gynécologie-Obstétrique, Hôpital Nord, Amiens, France

${ }^{7}$ Service de Pédiatrie et Génétique, Hôpital Nord, Amiens, France

${ }^{8}$ Service de Pédiatrie, CHU de Besançon, Besançon, France

${ }^{9} \mathrm{CHU}$ de Nantes, Service de Génétique Médicale, Nantes, France, et INSERM UMR 915, Institut du Thorax, Nantes, France

${ }^{10}$ Service de Cytogénétique, Hôpital Necker Enfants Malades, Paris, France
${ }^{11}$ Département de Génétique, Hôpital Necker Enfants Malades, Paris, France

${ }^{12}$ INSERM U781, Hôpital Necker Enfants Malades, Paris, France

${ }^{13}$ Service de Cytogénétique, Hôpitaux Universitaires de Strasbourg, Strasbourg, France

${ }^{14}$ Département de Génétique, Hôpitaux Universitaires de Strasbourg, Strasbourg, France

${ }^{15}$ Centre de Génétique et Centre de Référence Maladies Rares Anomalies du Développement et Syndromes Malformatifs, Hôpital d'Enfants, Dijon, France

${ }^{16}$ Service de Neurologie pédiatrique, Hôpital Bicêtre, Paris, France

${ }^{17}$ Service de Neuropédiatrie, Hôpital Necker-Enfants Malades, Paris, France

${ }^{18}$ Service de Cytogénétique, CHU de Dijon, Dijon, France

${ }^{19}$ Service de Cytogénétique Constitutionnelle, CBPE, Hospices Civils de Lyon, Bron France

Acknowledgements We wish to express our sincere gratitude to all the patients and their family who have participated in this study. We also thank the cytogenetics and molecular genetics staff from the different medical genetics departments. This study was supported by grants from the French Ministry of Health (DHOS-2007-2008).

Funding Other funders: French Ministry of Health (DHOS).

Competing interests None.

Patient consent Obtained.

Ethics approval This study was conducted with the approval of the university hospitals.

Provenance and peer review Not commissioned; externally peer reviewed

\section{REFERENCES}

1. Slavotinek AM. Novel microdeletion syndromes detected by chromosome microarrays. Hum Genet 2008:124:1-17.

2. Jacquemont ML, Sanlaville D, Redon R, Raoul O, Cormier-Daire V, Lyonnet S, Amie J, Le Merrer M, Heron D, de Blois MC, Prieur M, Vekemans M, Carter NP, Munnich A, Colleaux L, Philippe A. Array-based comparative genomic hybridisation identifies high frequency of cryptic chromosomal rearrangements in patients with syndromic autism spectrum disorders. J Med Genet 2006;43:843-9.

3. Harada N, Nagai T, Shimokawa 0, Niikawa N, Matsumoto N. A 4q21-q22 deletion in a girl with severe growth retardation. Clin Genet 2002;61:226-8.

4. Friedman JM, Baross A, Delaney AD, Ally A, Arbour L, Armstrong L, Asano J, Bailey DK, Barber S, Birch P, Brown-John M, Cao M, Chan S, Charest DL, Farnoud N, Fernandes N, Flibotte S, Go A, Gibson WT, Holt RA, Jones SJ, Kennedy GC Krzywinski M, Langlois S, Li HI, McGillivray BC, Nayar T, Pugh TJ, Rajcan-Separovic E, Schein JE, Schnerch A, Siddiqui A, Van Allen Ml, Wilson G, Yong SL, Zahir F, Eydoux $P$, Marra MA. Oligonucleotide microarray analysis of genomic imbalance in children with mental retardation. Am J Hum Genet 2006; 79:500-13.

5. Chelly J, Khelfaoui M, Francis F, Cherif B, Bienvenu T. Genetics and pathophysiopathology of mental retardation. Eur J Hum Genet 2006; 14:701-13.

6. Newey SE, Velamoor V, Govek EE, Van Aelst L. RhoGTPases, dendritic structure, and mental retardation. J Neurobiol 2005:64:58-74.

7. Pfeifer A, Aszódi A, Seidler U, Ruth P, Hofmann F, Fässler R. Intestinal secretory defects and dwarfism in mice lacking cGMP-dependent protein kinase II. Science 1996:274:2082-6.

8. Chikuda H, Kugimiya F, Hoshi K, Ikeda T, Ogasawara T, Shimoaka T, Kawano H, Kamekura S, Tsuchida A, Yokoi N, Nakamura K, Komeda K, Chung UI, Kawaguchi H. Cyclic GMP-dependent protein kinase II is a molecular switch from proliferation to hypertrophic differentiation of chondrocytes. Genes Dev 2004;18:2418-29.

9. Kugimiya F, Chikuda H, Kamekura S, Ikeda T, Hoshi K, Ogasawara T, Nakamura K, Chung UI, Kawaguchi H. Involvement of cyclic guanosine monophosphate-dependent protein kinase II in chondrocyte hypertrophy during endochondral ossification. Mod Rheumatol 2005:15:391-6.

10. Kawasaki Y, Kugimiya F, Chikuda H, Kamekura S, Ikeda T, Kawamura N, Saito T, Shinoda Y, Higashikawa A, Yano F, Ogasawara T, Ogata N, Hoshi K, Hofmann F, Woodgett JR, Nakamura K, Chung UI, Kawaguchi H. Phosphorylation of GSK-3beta by cGMP-dependent protein kinase II promotes hypertrophic differentiation of murine chondrocytes. J Clin Invest 2008;118:2506-15.

11. Uhler MD. Cloning and expression of a novel cyclic GMP-dependent protein kinase from mouse brain. J Biol Chem 1993;268:13586-91.

12. Serulle Y, Zhang S, Ninan I, Puzzo D, McCarthy M, Khatri L, Arancio O, Ziff EB. A GluR1-cGKII interaction regulates AMPA receptor trafficking. Neuron 2007:56:670-88

13. Serulle Y, Arancio 0, Ziff EB. A role for cGMP-dependent protein kinase II in AMPA receptor trafficking and synaptic plasticity. Channels (Austin) 2008;2:230-2. 